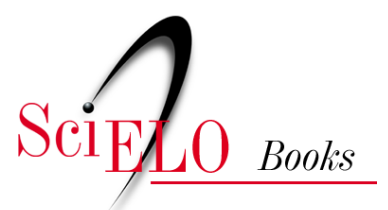

\title{
1 - O patrimônio inventado sob a tutela do Estado
}

\author{
Rozeane Porto Diniz \\ Ricardo de Aguiar Pacheco
}

\section{SciELO Books / SciELO Livros / SciELO Libros}

DINIZ, R. P., and PACHECO, R. A. O patrimônio inventado sob a tutela do Estado. In: OLIVEIRA, G. M. C., and VIEIRA, K. M. A., eds. Patrimônio, povos do campo e memórias: diálogos com a cultura, a arte e a educação [online]. Mossoró: EdUFERSA, 2020, pp. 17-31. ISBN: 978-65-87108-09-4. https://doi.org/10.7476/9786587108605.0002.

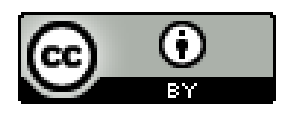

All the contents of this work, except where otherwise noted, is licensed under a Creative Commons Attribution 4.0 International license.

Todo o conteúdo deste trabalho, exceto quando houver ressalva, é publicado sob a licença Creative Commons Atribição 4.0. 


\section{O PATRIMÔNIO INVENTADO SOB A TUTELA DO ESTADO}

Rozeane Porto Diniz

Ricardo de Aguiar Pacheco

Pensar a política pública de preservação e valorização do patrimônio cultural no Brasil implica, necessariamente observar a trajetória do aparelho do Estado nacional dedicado a formular e implementar as ações de reconhecimento e valorização dos bens culturais em nível federal.

O Serviço do Patrimônio Histórico e Artístico Nacional (SPHAN) foi criado como órgão vinculado ao Ministério da Educação e Saúde por meio do Decreto-Lei no 25 de 1937 (BRASIL, 1937). Em 1946 essa repartição pública é renomeada para Departamento do Patrimônio Histórico e Artístico Nacional (DPHAN) (BRASIL, 1946). Em 1970 é renomeada para Instituto do Patrimônio Histórico e Artístico Nacional (IPHAN) e ganha como braço executivo de sua política o Instituto Pró-Memória (BRASIL, 1970). Por medida provisória do ano de 1990, esses órgãos são reagrupados no Instituto do Patrimônio Histórico e Artístico Nacional (BRASIL, 1990).

Percebam que essas alterações de nomeação não significaram a revogação das responsabilidades de atribuição de valor aos objetos culturais, mas pontual alteração da forma de atuação da autarquia em diferentes conjunturas do processo político da República. A criação na autarquia em 1937 estava ligada ao projeto político do Estado Novo. Ao passo que sua sucessiva renomeação esteve subordinada a projetos de reformas dos serviços administrativos do Estado. Em 1945 com processo de reabertura democrática. Em 1970 e o endurecimento do Governo Civil-Militar. Em 1990 como a redemocratização. 
Sem nos atermos a análises mais profundas do cenário político de cada um desses momentos desejamos, nesse momento, evidenciar como a autarquia responsável pelo reconhecimento e proteção dos bens culturais SPHAN, DPHAN, IPHAN — se ajustou e correspondeu ao projeto político mais amplo do Estado em cada um desses momentos históricos.

Nosso objetivo é demonstrar que o conceito de patrimônio foi redefinido e apropriado pelo Estado brasileiro em diferentes momentos do século XX, para legitimar uma política de reconhecimento, preservação e valorização cultural passando por atribuição de sentidos das formas mais variadas possíveis e atrelada a interesses específicos.

Autores como Gonçalves (1996, p. 33) nos alertam que é preciso questionar "Quem tem autoridade para dizer o que é e o que não é o patrimônio cultural brasileiro?". Ou seja, nos lembra que valor cultural de um objeto reconhecido pelo Estado como patrimônio nacional não está "dado a priori”, porque o objeto cultural não carrega valor per si. A caracterização de um determinado objeto enquanto patrimônio nacional é estabelecida através práticas administrativas e instituições político administrativas do Estado que materializam práticas discursivas e não discursivas sobre quais elementos caracterizam a identidade nacional.

Ao lado deste Marcia Chuva nos alerta para compreendemos que o patrimônio histórico está em concomitante e permanente construção e constante desconstrução, sendo fabricado, de acordo com os interesses dos sujeitos envolvidos nos atos de tombamento e (des)recaracterizados diante dos atos de (des)retombamentos.

[...] O patrimônio histórico e artístico nacional estava sempre em construção — não estava dado a priori. Não se deve perder de vista, portanto, que as visões de mundo e as posições nos diversos campos (político, cultural, religioso, intelectual etc.) determinaram, muitas vezes, as tomadas de posição dos agentes em jogo. Na gestão estatizada de bens simbólicos, escolhas políticas estavam permanentemente sendo feitas, as quais uma boa retórica era, de um modo geral, capaz de sustentar, no amplo universo de possibilidades de invenção do "patrimônio" (CHUVA, 2017, p. 239). 
Neste ensaio interpretativo do processo histórico de construção do patrimônio nacional vamos procurar interpretar a autarquia responsável pelo reconhecimento e proteção dos bens culturais como um "dispositivo histórico". Ou seja, como "um conjunto decididamente heterogêneo que engloba discursos, instituições, organizações arquitetônicas, decisões regulamentares, leis, medidas administrativas, [...] o dito e o não dito são elementos do dispositivo" (FOUCAULT, 1988, p. 244).

Portanto, não podemos tomar "patrimônio cultural" como uma categoria fechada e/ou mesmo linear. O termo patrimônio é operado no campo discursivo do dispositivo histórico que opera a política pública para o patrimônio cultural em acordo (ou dissonância) com os sentidos que lhe são atribuídos em cada tempo histórico. Sendo assim, a res/significação dessa categoria é plural e pode ser analisada em diversas dimensões.

Vejamos de forma contextualizada como o SPHAN/DPHAN/IPHAN enquanto "dispositivo histórico", é estrategicamente formulado e, consequentemente, como a categoria patrimônio é semantizada para dar sentido os objetos da cultura e, ao mesmo tempo, sustentação jurídica para as políticas públicas de patrimônio.

A bibliografia sobre o campo do patrimônio destaca que, na sua acepção dicionarizada, o termo patrimônio está ligado à herança do pai, aqueles bens que o progenitor deixa aos seus descendentes. Com o passar do tempo, esse sentido foi ampliando para designar, além dos bens de valor econômico e financeiro, também os bens culturais e simbólicos (CHOAY, 2006). Embora as preocupações com monumentos, considerados históricos, fossem mais antigas e datassem do século XVIII, é na virada para o século XX que o termo patrimônio entra na discussão em torno dos objetos culturais por parte dos Estados nacionais europeus e, vindo destes, chega ao Brasil.

Segundo Hartog (2006, p. 270), o "patrimônio não deve ser visto a partir do passado, mas a partir do presente, como categoria de ação do presente e sobre o presente". No Brasil, foi exatamente isso que aconteceu, o patrimônio foi significado de acordo com os interesses dos sujeitos e das relações de poder que norteavam as práticas de patrimonialização a cada tempo presente, a cada conjuntura política da república. 
Até a década de 1930, não tínhamos uma política institucionalizada em nível nacional que definisse, juridicamente, o patrimônio. É a partir do governo de Getúlio Vargas e o projeto de modernização da sociedade brasileira que uma política de cultura se legitima. Com a nomeação de Capanema para o Ministério da Educação e Saúde, em 1934, temos maior atenção a política cultural. Dito de outra forma, é a partir desse momento que o Estado começa a montar uma burocracia destinada a atuar junto ao campo da cultura. Graças a essa guinada para o campo cultural, temos as primeiras iniciativas concretas de criação de um órgão voltado ao estímulo do teatro, do canto coral, do rádio e do patrimônio cultural.

Em 1936, a convite de do Ministro Gustavo Capanema, Mario de Andrade elabora o "Anteprojeto para criação do Serviço do Patrimônio Histórico e Artístico Nacional” (ANDRADE, 1936). Embora esse Anteprojeto tenha sido um ensaio descartado por ser considerado "denso e polêmico, tanto nos detalhes do texto como na sua abrangência" (SANTOS, 2012, p. 4) ele previa, além de toda a estrutura administrativa que o órgão deveria ter em sua definição, uma definição muito ampla dos bens culturais que mereceriam proteção por parte do Estado. O fato é que o Anteprojeto não previa um instrumento de proteção legal eficaz. Soma de fatores que levou o a ser descartado pelo ministério.

Para resolver esse problema jurídico é chamado o advogado Rodrigo Melo Franco de Andrade que traz para a legislação o instrumento jurídico do tombamento. Tanto é assim que o Decreto-Lei no 25 de 1937, redigido por Rodrigo Melo Franco de Andrade é instituído como lei por Getúlio Vargas. Nesse o patrimônio cultural é juridicamente definido:

Art. $1^{\circ}$-Constitui o patrimônio histórico e artístico nacional o conjunto dos bens móveis existentes no país e cuja conservação seja de interesse público, quer por sua vinculação a fatos memoráveis da história do Brasil, quer por seu excepcional valor arqueológico ou etnográfico, bibliográfico ou artístico (BRASIL, 1937).

Aqui, temos a definição de patrimônio relacionado ao conceito dicionarizado de "herança do passado", porém não é qualquer herança, mas aquela que está vinculada a "fatos memoráveis da história do Brasil". O que pode 
ser considerado como memorável, em nossa história, é relativo e vai ser selecionado de acordo com a prática ideológica de quem está representado no poder executivo.

Para proteção do patrimônio cultural a legislação prevê o instrumento jurídico do tombamento como ato administrativo do Estado. Esse ato administrativo se materializa na inscrição do objeto cultural no Livro de Tombo. Procedimento legal que visa contornar o obstáculo do direito de propriedade uma vez que, não desapropriando impõe ao proprietário uma série de restrições ao uso do bem. Ao passo que lhe assegura outra série de garantias legais. Ou seja, não se trata de uma ação desinteressada, mas envolvida num universo político mais amplo que envolve uma prática seletiva, através do estado e dos atores sociais, designados para inventar e significar a categoria de patrimônio. E com ela a materializar a identidade nacional.

Mas para além de um com amparo legal para a proteção do patrimônio cultural era preciso um corpo de intelectuais, estrategicamente dispostos que dessem sustentação aos atos de tombamentos, que oferecessem legitimidade às práticas de patrimonialização. Antes mesmo da aprovação do Decreto, toda essa rede de relações já se formava, pois Rodrigo Melo Franco de Andrade preocupava-se com a efetividade, na prática, do órgão federal de preservação. Sua rede de relações era a "preparação para um terreno" que precisava ser fértil e não seria, talvez, apenas pela força da lei.

Para a difícil tarefa de dar efetividade ao SPHAN, inclusive com o necessário caráter nacional, Rodrigo contou com a contribuição de destacados profissionais das mais diversas áreas - arquitetos, juristas, engenheiros, historiadores, literatos, mestres de obras, entre outros (CALABRE, 2017, p. 37).

Rodrigo Melo Franco de Andrade se cercou dos intelectuais mais renomados e em regiões estratégicas com o intuito de estabelecer pontes nos diversos estados do Brasil. Com essa rede esperava que ocorressem tombamentos, de forma generalizada assim que o Decreto fosse aprovado. Dentre os intelectuais, podemos citar o sociólogo Gilberto Freyre, em Pernambuco; o historiador Augusto Meyer, no Rio Grande do Sul; os arquitetos como Lúcio Costa e Oscar Niemeyer; e os literatos como Carlos Drummond de 
Andrade e Manuel Bandeira. Tratava-se de intelectuais reconhecidos com atuação em diversas áreas e que fundamentavam um discurso de autoridade sobre o patrimônio cultural.

Para justificar o ato do tombamento, que implicava uma restrição ao direito de propriedade, foi criado um aparato administrativo que fazia uso desses intelectuais de diferentes campos do conhecimento e regiões do país para produzir um discurso de autoridade que legitimasse os processos de tombamento. Para observarmos essa burocracia como um "dispositivo histórico", destacamos o Conselho Consultivo e a Revista do SPHAN, ambos criados, concomitantemente, ao órgão federal de preservação.

O Conselho Consultivo estava previsto no Decreto $n^{\circ} 25$ de 1937, e foi instalado em 1938. Suas atribuições "concentravam-se na análise dos bens indicados para tombamento impugnados pelos proprietários, ou dos tombamentos solicitados pela sociedade civil" (CHUVA, 2017, p. 228). As ações do órgão eram, geralmente, em favor dos tombamentos e contra as impugnações. Na leitura atenta aos pareceres do Conselho é possível perceber e interpretar situações de conflito entre os conselheiros. Mas, ao fim dos debates, chegava-se à opinião unânime sobre como a autarquia estatal deveria agir para preservar o bem cultural.

Segundo Chuva (2017, p. 171), o Conselho Consultivo "atuava no sentido de dirimir possíveis conflitos, como uma instância superior, garantia o exercício de articulação discursiva a respeito da racionalidade, com o triunfo do 'interesse público', legitimando as práticas seletivas do SPHAN”. Portanto funcionava como um aparato do "dispositivo histórico" para legitimar as práticas de tombamento do SPHAN. Foi tudo tão estrategicamente disposto pelos agentes do estado que, independente das disputas e/ou resistências internas da autarquia, o que prevalecia como definição de patrimônio era o que era estabelecido pelo SPHAN.

A Revista era mais uma das publicações editoriais do SPHAN instrumentalizada para legitimar a definição de patrimônio e os atos de tombamento do órgão. Antes mesmo da aprovação do Decreto e organização do SPHAN, Rodrigo Melo Franco de Andrade, primeiro diretor do órgão, já articulava as primeiras publicações da Revista com artigos de intelectuais reconhecidos de diferentes regiões do país. 
Todavia o primeiro número circulou somente por volta de 1937 e "tinha o objetivo de veicular artigos que tratassem dos monumentos, apresentando-os e justificando a importância dos mesmos para o patrimônio nacional" (LANARI, 2010, p. 32-33). Entre os intelectuais que fizeram parte desse primeiro número da Revista, estavam Gilberto Freyre, Heloísa Alberto Torres, Lúcio Costa e Mario de Andrade (SPHAN, 1937). Cada um desses publicou artigo sugerindo quais monumentos mereciam um estudo de arte ou arqueológico em sua região. Sugeriam um plano de estudos com a análises de edificações como seminários, igrejas e capelas que representavam a arquitetura barroca colonial. Dessa forma, esses atuavam como parte do dispositivo histórico que legitimava a definição de patrimônio que seria operacionalizada pela autarquia.

Apesar de os discursos, na Revista, no Conselho Consultivo e no SPHAN, sobre tombamentos e registros terem como justificativa os discursos que enaltecem e valorizam o passado colonial, esses buscam legitimar práticas de poder do presente.

Ao fazermos um balanço do que foi tombado durante todo o período histórico do Estado Novo, vemos que os tombamentos (IPHAN, 1938-1940, 1940-1950) são, em sua ampla maioria, edificações da igreja católica ou fortificações militares. Também percebemos nessas atas que a justificativa de praticamente todos os bens tombados era seu enquadramento no estilo artístico e arquitetônico como barroco colonial.

Visto nessa contextualização, o SPHAN pode ser interpretado como um "dispositivo histórico" estrategicamente concebido e operacionalizado para reconhecer e proteger os bens culturais elegidos como patrimônio cultural representativo da nação. Autarquia estatal que opera juridicamente uma política pública de cultura claramente orientada por uma determinada narrativa sobre o passado que se deseja preservar num determinado tempo presente.

Apenas no ano de 1967 Rodrigo Melo Franco de Andrade é substituído por Renato Soeiro na direção da autarquia. Renato Soeiro era arquiteto e funcionava como "braço direito" de Rodrigo. Era o principal representante 
do órgão nacional nos encontros internacionais e, por isso, estava atualizado com os debates internacionais e as ressignificações que sofria a concepção de patrimônio a nível mundial.

Assim que assumiu, Renato Soeiro trouxe ao órgão federal de preservação as orientações e conceitos relacionados ao patrimônio, que foram discutidos e/ou ampliados pela Carta de Veneza (ICOMOS, 1964) e pelas Normas de Quito (OEA, 1967). Com isso, na gestão de Renato Soeiro, "os tombamentos passaram a ser compreendidos, enfim, como instrumento de política urbana no contexto de um Estado desenvolvimentista" (SOPHIA, p. 325).

Pode ser entendido como reflexo dessa reorientação da autarquia a sua reorganização administrativa que implicou na criação da Fundação Pró-memória, que financiava e executava obras de restauro e conservação de espaços urbanos. Essa guinada, nas práticas de patrimonialização, havia sido iniciada com as orientações advindas da Unesco que alertavam para a relação entre o turismo e o patrimônio cultural, porém com vistas à questão econômica.

Se os bens do patrimônio cultural desempenham papel tão importante na promoção do turismo, é lógico que os investimentos que se requerem para a sua devida restauração e habilitação específica devem se fazer simultaneamente aos que reclama o equipamento turístico e, mais propriamente, integrar-se num só plano econômico de desenvolvimento regional (OEA, 1967, p. 7).

Com a ampliação e ressignificação do patrimônio, as orientações internacionais sobre o patrimônio chegam ao Brasil no momento do recrudescimento do regime político e implementação dos projetos de crescimento econômico acelerado. A gestão de Soeiro se destaca pelos tombamentos dos conjuntos arquitetônicos com forte potencial turístico, como o caso de Olinda. Ao todo foram 130 bens tombados, o que ilustra a efervescência das práticas de patrimonialização. Nos 12 anos de sua gestão: 
foram dados passos definitivos e fundamentais para a modernização do sistema estatal de preservação do patrimônio, assim como viabilizados os meios financeiros e materiais para o desencadeamento desse processo. Assim, pode-se afirmar que a "fase moderna" da preservação no Brasil começa com Renato Soeiro (SAPORETTI, 2017, p. 43).

Segundo Saporetti, Soeiro que tentou obter recursos financeiros com organismos internacionais para viabilizar a modernização das práticas de patrimonialização no Brasil, dando sequência ao que fazia ainda sob a direção de Rodrigo Melo Franco de Andrade.

Desta forma percebemos que Renato Soeiro opera o dispositivo histórico da autarquia a partir de outro regime discursivo. O discurso de autoridade da autarquia agora se baseia nas orientações dos organismos internacionais. Com esse discurso minimizava o impacto financeiro da ação de tombamento sobre a propriedade apontando que a política cultural de reconhecimento e preservação do patrimônio cultural agregava valor econômico por meio da atividade do turismo.

Em 1979, Aloísio Magalhães assume a gestão da autarquia responsável pela preservação do patrimônio cultural após ter atuado por 5 anos na direção do Centro Nacional de Referência Cultural. Falecendo ainda em 1982 no exercício do cargo deixou sua ação incompleta, mas nesses dois órgãos federais, assim como em outras ações que dirigiu, o designer pernambucano promoveu uma guinada nas políticas públicas destinadas ao patrimônio cultural:

opera uma significativa ampliação semântica do conceito de patrimônio cultural, que a partir de então passa a incorporar, progressivamente, os bens culturais de natureza imaterial ou intangível e, dentre esses, as manifestações da cultura popular (ANASTASSAKIS, 2017, p. 65).

Uma mudança percebida na sua gestão é o olhar para outras regiões do país promovendo estudos para o tombamento de bens culturais em diferentes regiões do país diminuindo a desigualdade na estatística dos bens tombados em relação ao Sudeste. 
Ainda que não tenha promovido a alteração da legislação para contemplar a patrimonialização dos bens culturais imateriais sua gestão amplificou esse debate conceitual no interior da autarquia e na reorientação da política cultural para o patrimônio.

No contexto Nacional, precisamos considerar que o país passava por um processo de abertura política e consequente reabertura para a democracia, uma vez que a gestão de Aloísio Magalhães vai de 1979 a 1982. Aloísio tenta incorporar as políticas de patrimônio nessa abertura política,

na tentativa de ampliação democrática do conceito de patrimônio [...], Aloísio propôs a absorção, dentro das políticas públicas de preservação, das manifestações culturais ligadas às matrizes africana e indígena, bem como a consideração das colocações das comunidades habitantes das cidades históricas contempladas por políticas de preservação (ANASTASSAKIS, 2017, p. 67-70).

Obviamente, a ampliação do conceito de patrimônio não se deu sem conflitos, pois a democratização do conceito gerou reformulações nas políticas públicas de patrimônio, relacionada não mais ao tombamento, mas ao diálogo com o "povo", para que os registros das manifestações pudessem acontecer. No entanto essas políticas só se concretizam de fato com a provação do Decreto 3.551 de 2000 que institui o registro de bens culturais de natureza imaterial (BRASIL, 2000).

Aloísio Magalhães reacende debates relacionados ao reconhecimento e valoração dos saberes populares ao patrimônio que estava presente no Anteprojeto de Mario de Andrade. E, assim como na década de 1930, o debate na década de 1970 gerou muita polêmica e resistência. Antigos debates teóricos e ressentimentos políticos que opõe cultura e folclore, popular e erudito se chocaram. Termos e objetos que, no debate antropológico dos anos 1970, foram identificados e valorizados como práticas culturais dignas de reconhecimento e de valor cultural. Segundo Gonçalves (1996), a substituição da expressão "patrimônio histórico e artístico" por "bens culturais" traz uma visão para o patrimônio voltada para o presente e não mais para o passado, revisando novamente a perspectiva sobre patrimônio da autarquia responsável pela implementação da política cultural. 
Assim, mesmo ficando à frente da gestão do IPHAN por apenas três anos, tendo em vista o seu falecimento em 1982, Aloísio Magalhães instaura discussões que, mesmo não sendo implementadas, foram importantes para a ampliação do conceito de patrimônio reconhecido pelo Estado. O dispositivo histórico, a autarquia responsável pelo reconhecimento e proteção dos bens culturais, mobilizou os debates teóricos e as demandas sociais emergentes no contexto histórico da década de 1970 para seguir definindo os objetos culturais que têm valor de memória para o Estado Nacional.

\section{Considerações Finais}

Nossa reflexão teórica sobre o conceito patrimônio cultural compreende que essa ferramenta está em constante reelaboração. Já nossa observação empírica sobre os objetos culturais percebe que esses estão em dinâmica modificação. Logo o estudo empírico dos objetos culturais com o conceito teórico do patrimônio implica reconhecer que trabalhamos com duas variáveis. A variável do objeto cultural, que se transforma no tempo; e a variável do conceito, que se aperfeiçoa com o uso.

Refletir sobre a história da autarquia responsável pelo reconhecimento e proteção dos bens culturais no Brasil - SPHAN, DPHAN, IPHAN — ao longo do século XX nos permite evidenciar como esse dispositivo histórico mobilizou sujeitos históricos com diferentes visões e motivações para a preservação do passado.

O objeto do discurso do patrimônio histórico e artístico nacional foi selecionado entre o amplo conjunto de bens culturais disponíveis. Gerações sucessivas de sujeitos foram reformulando e ampliando os valores e significados procurados, mas sempre operou com a seleção. De edificações caracterizadas como barroco-colônia, rapidamente chegou-se às formas urbanísticas do modernismo. Das práticas religiosas católicas, lentamente se chega aos terreiros de candomblé. Sempre escolhendo um conjunto de objeto em detrimento de outros.

Para legitimar esse discurso edificou lugares de enunciação que elevavam o discurso e os sujeitos a posição de autoridade. A autarquia formalizou espaços de enunciação como o conselho consultivo, mas também os editais 
de financiamento. Regras administrativas tanto para o tombamento dos bens materiais como para o registro da cultura imaterial que, de forma kaficaniana, dificultam o movimento dos não iniciados.

Mecanismos de tal sorte imbricados e entrelaçados que a instituição estatal responsável pelo reconhecimento e preservação dos bens culturais mantém enunciando que o reconhecimento de um objeto cultural como patrimônio cultural necessita de uma atribuição de valor externa ao objeto e a cultura que o produz. Sejam os intelectuais mobilizados na primeira gestão da autarquia, sejam as referências internacionais da segunda gestão ou mesmo a valorização econômica da arte popular. Em todos os momentos vemos sujeitos externos ao grupo social que faz uso do objeto cultural reconhecendo e atribuindo valores e significados ao bem tombado.

Compreendemos que o patrimônio histórico está em permanente transformação, seu significado é constantemente reformulado para incorporar demandas tanto das forças sociais que clamam por reconhecimento cultural como os interesses políticos que mobilizam a força estatal. Diante das relações de poder e das disputas de narrativas em torno do ato de tombamento, alguns objetos podem ser irrisórios, historicamente, mas podem se tornar importantes se forem tocados pelos sujeitos que têm autoridade para tombar. 


\section{REFERÊNCIAS}

ANASTASSAKIS, Z. A Cultura como projeto: Aloisio Magalhães e suas ideias para o Iphan. Revista do Patrimônio Histórico e Artístico Nacional, n. 35, 2017.

BRASIL. Decreto $n^{\circ}$ 3.551, de 04 de agosto de 2000. Institui o Registro de Bens Culturais de Natureza Imaterial que constituem patrimônio cultural brasileiro, cria o Programa Nacional do Patrimônio Imaterial e dá outras providências. Diário Oficial da União, Brasília, DF, 07 ago. 2000. Disponível em: https://bit.ly/2GwcNcF. Acesso em: 05 maio 2020.

BRASIL. Decreto n ${ }^{\circ}$ 66.967, de 27 de julho de 1970. Dispõe sobre a organização administrativa do Ministério da Educação e Cultura. Diário Oficial da União, Brasília, DF, 03 ago. 1970. Disponível em: https://bit. ly/3gXoh5k. Acesso em: 05 mai. 2020.

BRASIL. Decreto-lei no ${ }^{\circ}$, de 30 de novembro de 1937. Organiza a proteção do patrimônio histórico e artístico nacional. Diário Oficial da União, Rio de Janeiro, 06 dez. 1937. Disponível em: https://bit. ly/2Z1123Z. Acesso em: 05 mai. 2020.

BRASIL. Decreto-lei n ${ }^{\circ}$ 8.534, de 2 de janeiro de 1946. Passa a Diretoria do Patrimônio Histórico e Artístico Nacional o Serviço do mesmo nome, criado pela Lei número 378, de 13 de janeiro de 1937, e dá outras providências. Diário Oficial da União, Rio de Janeiro, 04 jan. 1946. Disponível em: https://bit.ly/3boyXZy. Acesso em: 05 mai. 2020. 
BRASIL. Medida Provisória n ${ }^{0}$ 151, de 15 de março de 1990. Dispõe sobre a extinção e dissolução de entidades da Administração Pública Federal e dá outras providências. Diário Oficial da União, 15 mar. 1990. Disponível em: https://bit.ly/2QOJN1s. Acesso em: 05 mai. 2020.

CALABRE, Lia. O Serviço do Patrimônio Artístico Nacional dentro do contexto da construção das políticas públicas de cultura no Brasil.

Revista do Patrimônio Histórico e Artístico Nacional, n. 35, 2017. CHOAY, Françoise. A Alegoria do patrimônio. Tradução de Luciano Vieira Machado. 4. ed. São Paulo: Estação Liberdade: UNESP, 2006.

CHUVA, Márcia. Os arquitetos da memória - sociogênese das práticas de preservação do patrimônio cultural no Brasil (anos 1930-1940). Rio de Janeiro: EdUFRJ, 2017.

FONSECA, Maria Cecília Londres. O patrimônio em processo: trajetória da política federal de preservação no Brasil. 2. ed. Rio de Janeiro: EdUFRJ; IPHAN, 2005.

FOUCAULT, Michel. Microfísica do Poder. Rio de Janeiro: Edições Graal, 1988.

FOUCAULT, Michel. A ordem do discurso: aula inaugural no Collège de France, pronunciada em 2 de dezembro de 1970. Campinas: Loyola, 1996.

FUNARI, Pedro Paulo; PELEGRINI, Sandra de Cássia Araújo.

Patrimônio Histórico e Cultural. 2. ed. Rio de Janeiro:

Jorge Zahar, 2009.

GONÇALVES, José Reginaldo Santos. A Retórica da Perda: os discursos do patrimônio cultural no Brasil. Rio de Janeiro: EdUFRJ; IPHAN, 1996.

GONÇALVES, José Reginaldo Santos. O Mal-estar no Patrimônio: identidade, tempo e destruição. Estudos Históricos, v. 28, n. 55, p. 211-228, jan./jun. 2015.

HARTOG, François. Tempo e Patrimônio. Varia História, v. 22, n. 36, p. 261-273, jul./dez. 2006. 
IPHAN. Revista do Serviço do Patrimônio Histórico e Artístico Nacional, v. 1, 1937.

\section{IPHAN. Atas do Conselho Consultivo do Patrimônio Cultural:}

1938-1940/ 1940-1950. Disponível em: http://portal.iphan.gov.br/

atasConselho?data=1938\%2F1940. Acesso em: 04 jun. 2020.

ICOM. Carta de Veneza. Rio de Janeiro: IPHAN, 1964. Disponível em: https://bit.ly/3lPMhuD. Acesso em: 04 jun. 2020.

LANARI, Raul Amaro de Oliveira. Patrimônio por Escrito: a política editorial do Serviço do Patrimônio Histórico e Artístico Nacional durante o Estado Novo (1937-45). 2010. 207 f. Dissertação (Mestrado em História) - Universidade Federal de Minas Gerais, Belo Horizonte, 2010.

OEA. Normas de Quito. Rio de Janeiro: IPHAN, 1967. Disponível em: https://bit.ly/3bpC7fv. Acesso em: 04 jun. 2020.

SAPORETTI, Carolina Martins. A gestão de Renato Soeiro na direção da DPHAN (Diretoria do Patrimônio Histórico e Artístico Nacional) (1967-1979). 134 f. Dissertação (Mestrado em História) Universidade Federal de Juiz de Fora, Juiz de Fora, 2017.

SANTOS, Cecília Rodrigues dos. A Noção de patrimônio e a origem das ideias e das práticas da preservação no Brasil. Arquitextos, ano 13, n. 149, out. 2012.

SCHLEE, Andrey Rosenthal; QUEIROZ, Hermano. O jogo de olhares. Revista do Patrimônio Histórico e Artístico Nacional, n. 35, 2017. SOPHIA, Daniela Carvalho. As Políticas de preservação do patrimônio na arena federal sob a gestão de Renato Soeiro (1967-1979). In: Marcus Granato (Org.). Coleção MAST: 30 anos de pesquisa. Rio de Janeiro: Museu de Astronomia e Ciências Afins, 2015. v. 1. p. 316-339.

WILLIAMS, Daryle. Gustavo Capanema, ministro da cultura. In: GOMES, Angela de Castro (Org.). Capanema: o ministro e seu ministério. Rio de Janeiro: Editora FGV, 2000. 